DISTRIBUTION STATEMENT A. Approved for public release; distribution is unlimited.

\title{
Multiscale Study of Currents Affected by Topography
}

\author{
Bruce D. Cornuelle \\ Scripps Institution of Oceanography \\ University of California San Diego \\ Mail Code 0230 \\ La Jolla, CA 92093-0230 \\ Phone: (858) 534-4021Ｆax: (858) 534-9820Ｅmail: bcornuelle@ucsd.edu
}

Award Number: N00014-13-1-0479

\section{LONG-TERM GOALS}

This work seeks to understand the effects of topography on the ocean general and regional circulation with a focus on the wide range of scales of interactions. The small-scale details of the topography and the waves, eddies, drag, and turbulence it generates (at spatial scales ranging from meters to mesoscale) interact in the boundary layers to influence the larger-scale flow. We will study these issues through ocean model simulations, adjoint sensitivity experiments, and state estimation using measurements in the region surrounding an island in the westward-flowing limb of the subtropical gyre.

\section{OBJECTIVES}

The objectives of this program include addressing number of questions on ocean circulation that arise near islands and abrupt topography. Questions to study include:

- What is the steady-state flow around the feature, including isopycnal depths, currents, and water mass characteristics? How do these vary with changes in the surrounding large-scale flow and atmospheric forcing?

- What is the response of the local flow to time-dependent large-scale flow? i.e., how does the feature scatter incoming barotropic and baroclinic Rossby waves (as well as nearinertial waves and tides), into outgoing waves, mean flows, and topographically-trapped and damped waves?

- How much can be learned about the regional circulation or the larger scale currents from local observations? Can they be used for linear or nonlinear inverse estimates? i.e., can the regional or gyre circulation be monitored from pressure gauges, temperature sensors, current meters, or other measurements near the feature?

- The influence of the boundaries on the flow in the nested inner model can also be turned around to study how the feature influences the larger-scale boundary flow. Example questions are: what form drag is exerted on the larger scale flow? How far eastward, or "upcurrent" does the influence of the feature extend? How turbulent are the wakes? Are eddies shed? If so, do shed eddies create counter-currents in the wake of the feature? 


\section{Report Documentation Page}

Form Approved

OMB No. 0704-0188

Public reporting burden for the collection of information is estimated to average 1 hour per response, including the time for reviewing instructions, searching existing data sources, gathering and maintaining the data needed, and completing and reviewing the collection of information. Send comments regarding this burden estimate or any other aspect of this collection of information,

including suggestions for reducing this burden, to Washington Headquarters Services, Directorate for Information Operations and Reports, 1215 Jefferson Davis Highway, Suite 1204, Arlington

VA 22202-4302. Respondents should be aware that notwithstanding any other provision of law, no person shall be subject to a penalty for failing to comply with a collection of information if it

does not display a currently valid OMB control number.

1. REPORT DATE

30 SEP 2014

4. TITLE AND SUBTITLE

Multiscale Study of Currents Affected by Topography

6. $\operatorname{AUTHOR}(\mathrm{S})$

7. PERFORMING ORGANIZATION NAME(S) AND ADDRESS(ES)

University of California San Diego,Scripps Institution of Oceanography,9500 Gilman Drive,La Jolla,CA,92093

9. SPONSORING/MONITORING AGENCY NAME(S) AND ADDRESS(ES)

\section{DATES COVERED}

00-00-2014 to 00-00-2014

5a. CONTRACT NUMBER

5b. GRANT NUMBER

5c. PROGRAM ELEMENT NUMBER

5d. PROJECT NUMBER

5e. TASK NUMBER

5f. WORK UNIT NUMBER

8. PERFORMING ORGANIZATION REPORT NUMBER

10. SPONSOR/MONITOR'S ACRONYM(S)

11. SPONSOR/MONITOR'S REPORT NUMBER(S)

12. DISTRIBUTION/AVAILABILITY STATEMENT

Approved for public release; distribution unlimited

13. SUPPLEMENTARY NOTES

14. ABSTRACT

15. SUBJECT TERMS

16. SECURITY CLASSIFICATION OF:

a. REPORT

unclassified b. ABSTRACT

unclassified c. THIS PAGE

unclassified
17. LIMITATION OF ABSTRACT

Same as

Report (SAR)
18. NUMBER 19a. NAME OF

OF PAGES RESPONSIBLE PERSON

4 


\section{APPROACH}

We will explore and answer these questions through numerical model-based data analysis, including state estimation in nested domains. We will use assimilated global HYCOM and the MIT general circulation model (MITgcm) in nested domains starting from basin scale, connected to high-resolution (sub km) inner domains modeled with Delft3D or ROMS within about a degree of the island which will be configured and run by other investigators. Our results will be used in collaboration with other investigators to plan the experiments and to help to understand the observations. We will use the ocean models to provide a dynamically-consistent re-analysis of the observations in the region, both from the experiment and from other sources (Argo, Altimetry, SST, TAO, etc.).

\section{WORK COMPLETED}

We have been investigating model representations of the interactions of the NEC with the archipelagos and ridges in the western Tropical Pacific using analyses from both global HYCOM/NCODA and MITgcm state estimates. This is an area where topography varies much faster than allowed by QuasiGeostrophic theory, and it is not clear how well the large-scale models adequately represent the physics of the topographic interactions. In addition to the HYCOM output, we are using a complete Tropical Pacific model $\left(1 / 3^{\circ}\right.$ horizontal resolution, $30^{\circ} \mathrm{S}$ to $\left.30^{\circ} \mathrm{N}\right)$ as well as a regional $1 / 6^{\circ}$ model originally developed for the ONR project "Origins of the Kuroshio and Mindanao Currents" (OKMC). Both models include state estimation. The basin model resolves wind-forced currents propagating westward approximately along Rossby wave characteristics as can be seen by calculations of the sensitivity of western boundary transport to wind stress [Zhang, et al. 2012]. A comparison of the SSH estimates from 2010-2011 from AVISO, a free forward simulation of the OKMC regional model using HYCOM/NCODA initial and boundary conditions, and Tropical Pacific and OKMC regional state estimates using existing data (such as Argo, SST, and SSH) is shown in Figure 1(a,b,c) for three $1^{\circ}$ by $1^{\circ}$ boxes just to the east of Palau, Yap, and Guam, respectively. Although the AVISO map is only an estimate, it is taken as truth for these comparisons. The state estimates used along-track SSH from three satellites (Jason-1, Jason-2 and Envisat) from the RADS database, so they are not required to match mapped AVISO SSH exactly. The free model simulation reproduces some of the SSH variability, but often has quite large errors. The OKMC estimate is best for Palau, which is well inside its domain of interest, but the Tropical Pacific estimate is generally better for Yap and Guam, which are near the eastern boundary of the OKMC regional model, and do not change much from the HYCOM solution due to the influence of the HYCOM boundary conditions. The AVISO estimates show similarities between Palau and Yap (Figure 1d), which is expected since Yap is just to the east of Palau, and westward-propagating features should show up similarly at both locations. In this comparison, the phase lag seems to be about 1 month, but there are significant differences, due to local wind stress, observation error, or alternative pathways.

The state estimates will be used for diagnosis of the physical processes active around the features after comparisons with independent observations, testing the model hindcasts and forecasts. For example, the model performance in the highly-stratified positive-wind-curl region is quite sensitive to the assumed vertical diffusivity coefficient. We are taking guidance from estimates of the diffusivity from Argo (Whalen, Talley, and Mackinnon, 2012) and refining the background diffusivity estimates for this region. The state estimates are being re-run with other adjusted parameters, such as viscosity, and with varying assimilation windows to see how long an assimilation window can be used and how well the estimates perform in forecasts. 
In addition, MITgcm simulations of an idealized, flat-bottom, rectangular ocean basin containing an idealized island are being used to study the sensitivity of transport to wind stress in the vicinity of the island and through the section connecting the island to the eastern boundary, generalizing the island rule. This is being compared to simpler, semi-analytic island rule streamfunction calculations, although the idealized calculations are surprisingly complicated and hard to get right (Kessler, personal communication).

\section{RESULTS}

The waveguides present in the basin (through beta and topography) determine the pathways of control of the transport, and are hypothesized to correspond to the integration contour for the island rule calculation, although sharp dependence on a single latitude is not observed.

\section{IMPACT/APPLICATIONS}

The boundary current transport sensitivity to local and basin-wide wind stress is quantified for timedependent cases with arbitrary topography and existing background flows.

\section{RELATED PROJECTS}

\section{REFERENCES}

Whalen, C.B., Talley, L.D., and MacKinnon, J.A., 2012, "Spatial and temporal variability of global ocean mixing inferred from Argo profiles”, Geophysical Research Letters, 39.

\section{PUBLICATIONS}



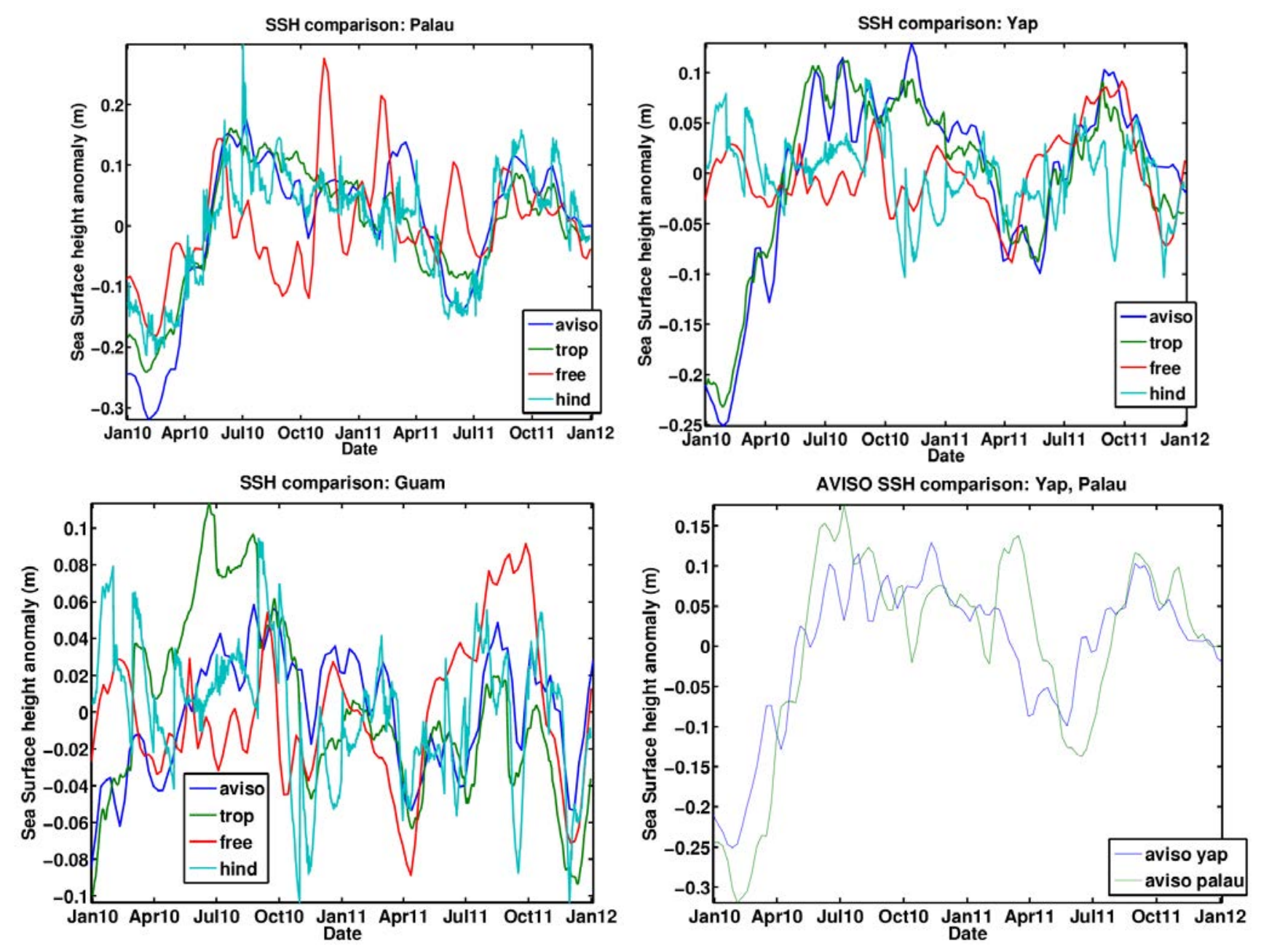

Figure 1 a,b,c: Comparison of AVISO mapped SSH (blue line) with a free 1/6 degree OKMC regional simulation (red line), a Tropical Pacific state estimate made over 2 month intervals (green line), and a state estimate for the OKMC regional model using one month assimilation windows

(cyan). The values are averages in $1^{\circ}$ by $1^{\circ}$ boxes just to the east of Palau, Yap, and Guam, respectively. 1d is a comparison of the AVISO SSH for Yap (blue) and Palau (green), repeated from figures $1 a$ and $1 b$. 